\title{
Pollen Findings in a Presumptive Drowning Case
}

\author{
Pilar Martínez ${ }^{1}$, Amelia González-Porto ${ }^{2}$, Manuel Munuera ${ }^{3}$, Natalia Acevedo ${ }^{4}$ \\ ${ }^{1}$ Biology Service, National Institute of Toxicology \& Forensic Science, Madrid, Spain \\ ${ }^{2}$ Beekeeping Centre, Marchamalo Agrarian Centre, Guadalajara, Spain \\ ${ }^{3}$ Department of Agricultural Science Technology, Botanic Area, Higher Technical School of Agricultural \\ Engineering, Cartagena, Spain \\ ${ }^{4}$ Institute of Legal Medicine, Toledo, Spain \\ Email: ${ }^{*}$ ilarm.fernandez@justicia.es
}

Received 2 February 2015; accepted 20 March 2015; published 26 March 2015

Copyright (C) 2015 by authors and Scientific Research Publishing Inc.

This work is licensed under the Creative Commons Attribution International License (CC BY). http://creativecommons.org/licenses/by/4.0/

(c) (†) Open Access

\begin{abstract}
A medicolegal/botanical collaboration has to lead to an interdisciplinary procedure for developing methods when studying dead bodies found in water with no clear circumstances. Hereby we present a report or a preliminary attempt as a basis for encouraging further work in the field. The body of an unidentified 25 - 35 years old woman was found immersed in a fresh water ditch in state of decomposition. Structural alterations avoid any $a$ priori identification of asphyxia or traumatic cervical lesions. The last cause of death was estimated as a cardio respiratory collapse and a drowning investigation was proposed. Taxonomic species identification was carried out to relate the pollen aspiration with the water medium in lung, spleen, liver and water medium. We presented pollen grains in spleen, as a closed organ, as a clue for death investigation in the absence of diatom findings. Information about where and when pollen grains occur may ascertain that a body or an object was in some place at a certain time. Since the consequences of aspiration depend on many factors, such as the quantity, size and solidity of the material aspirated and whether the aspiration is chronically recurrent or acute, the pollen investigation must be done with precaution. We conclude that in the absence of other microscopic structures, biochemical blood analyses, or histological findings, forensic palynology may be of help to relate the presumptive drowned body with its death scenario.
\end{abstract}

\section{Keywords}

Pollen Grains, Drowning, Palynology, Immersion, Diatoms

\footnotetext{
*Corresponding author.
} 


\section{Introduction}

Forensic palynology has been a law enforcement tool in solving legal issues, either civil or criminal, for over 50 years [1]. The forensic botanic analysis consists of species identification and an estimation of the percentage that each plant species represents in an evidentiary sample [2]. It refers mainly to the study of pollen and spores, together with microscopic bodies such as dinoflagellates, diatoms and other microfossils. Its evidence can reveal not only the particular season, but also the geographical origin. Information about where and when pollen grains occur may ascertain that a body or an object was in a certain place at a certain time. Spores will refer to the reproductive bodies of ferns, mosses and fungi. An obvious use has been in examination of soil caught up in the commission but there are also significant implications for revealing the timing of the generation of documents, etc. [3]. There are other not so usual items that have been little investigated and forensic palinology has been an underutilised form of trace evidence [1] [3].

Drowning, as water aspiration to death, has extensively been discussed in medicolegal cases, and immersions are commonly solved by diatoms (microalgae), strontium (Sr) and other trace elements analyses [4]-[9]. Some drownings are sometimes difficult to resolve and a joint determination of $\mathrm{Sr}$ and other biochemical markers like Fe has been recommended [9] [10]. However, haemodilution is not so evident in some samples [9] and other form elements might be relevant apart from diatoms. Besides, significant differences in the amount of strontium absorbed into the bloodstream from fresh water are much lower than in seawater [6] and that is an inconvenience for diagnosis resolving. Freshwater drownings (FWD) are even more difficult to research if no blood can be analysed because of the long post-mortem interval (PMI). Hereby the pollen study recovers importance when diatoms and microalgae are absent in the analysed organs. To this respect, there is very scarce mention or no mention of pollen with relation to drowning or the diagnosis of death in literature [11]. We present a FWD case and the correlated information of death circumstances, autopsy and microscopic findings, suggesting the pollen analysis as one optional tool for forensic diagnosis.

\section{Case History}

The body of an unidentified 25 - 35 years old woman was found immersed in a ditch (deposited freshwater medium) in spring time (between $20^{\text {th }}$ March and $10^{\text {th }}$ April) closed to Torrijos geographical area in a Mediterranean vegetation surrounding (Toledo, Spain). An advanced state of body decomposition and severe tissular lysis was observed. The structural alteration avoided any a priori conclusion with respect to asphystic or traumatic cervical lesions or extrinsic violence. The last cause of death was estimated as a lung-cardiac collapse. In the absence of other data, a drowning microscopic investigation was proposed.

\section{Materials and Methods}

Water-medium (500 mL) and fresh organs (left-lung, spleen and liver) were shipped to the National Institute of Toxicology \& Forensic Science (INTCF, Madrid). Tissue samples (10 g) were cleaned with ultrapure type I water for 5 minutes (min) and prepared for diatom (silica-structures) analysis with nitric acid $\left(65^{\circ}\right)$ and K-proteinase in $0.01 \mathrm{M}$ Tris-ClH buffer, following centrifugation (2500 r.p.m. for $7 \mathrm{~min}$ ). One $\mathrm{mL}$ sediments were placed in dissolution with $4 \mathrm{~mL}$ distilled water following microfiltration with cellulose membrane $(1.2 \mu \mathrm{m}$ pore diameter) and set over glass-slides for drying at $56^{\circ} \mathrm{C}$; once dried 2 - 3 immersion oil drops were added on top of the slide for transparency to allow light microscopic visualization $(10 \times, 40 \times, 100 \times)$. Counts of diatom valves at high magnification were yielded from the strewn slides. A comparison, when possible, was carried between organs findings and water-medium. Chirurgic material was treated with chlorine so the possibility of posterior sample contamination at the lab manipulation was discharged. The identification of pollen grains and nomenclature were performed using the classical methodology and identification keys following Valdés et al. (1987) [12] and Moore et al. (1991) [13]. The main purpose of the investigation presented here was oriented to find diatoms, and even though, pollen grains were seen and identified, so no special technique for pollen collection was applied. Similarly, no information about pollen concentrations in the air could be compared a posteriori with those found in the water medium and samples analysed. It is possible that for future analysis results accuracy may be improved if the classical methods from the palinology investigation are applied.

\section{Results and Discussion}

Diatoms were found in the fresh-water medium but not in lung, spleen and liver analysed. However, pollen 
grains were encountered in spleen (9 specimens found) and lung $(\mathrm{N}=12)$ (closed and open organs, respectively), as well as in the water-medium ( $\mathrm{N}=7$ ), and lacked in the liver (Table 1). Because of the low individuals number no statistical analysis could be carried out. The identification included the types $(\mathrm{t})$ of plants with similar pollens and species as follows: Cytisus t., Trifolium t., Pinus t., Rosaceae (possibly Rubus t.) and Quercus caducifolium. We could differentiate Trifolium t. pollen grain trizonocolporate with three apertures (Figure 1(A)) and Pinus t. with the pollen body (b) and two air sacs (Figure 1(B)). Similar types of pollen grains found in water medium (negative control) were also present in the lung and spleen. The spleen is as a closed organ, and the pollen presence may be indicative of aspiration, at least as a proof of an income. Such fact acquires significance since entry of structures, as diatoms, from the lungs and through the digestive tract into the systemic circulation had been proved to lead to positive results [14]. By contrast, microalgae and other foreign bodies present in open organs (gastric and pulmonary contains) may have penetrated post-mortem [7]. In the present case, the finding of pollen in the closed organs may be indicative of a lively aspiration either by air or through the water-medium but there is no literature to this respect. Somehow, immersion artefacts may occur in any corpse immersed in water, irrespective of whether death was from drowning or the person was dead on entering the water. In our present case, the aspiration, either by air or by water is not ascertain. Our victim might have been in contact with the found plant species elsewhere, but like it occurred in other medicolegal cases, detailed investigations indicated that this was unlikely because of the moderate percentage of pollen presence encountered [1]. Similar findings of pollen grains were described in water medium and analysed organs in the present case (Table 1, Figure 1). Thus, we can confirm the water medium as our control sample with respect to the sample results, and considering that such number of pollen grains is not usual to be found in current drowning identifications at the forensic laboratory (unpublished).

The consequences of aspiration depend on many factors, such as the quantity, size and solidity of the material aspirated and whether the aspiration is chronically recurrent or acute [15]. The only similar representative description with pollen grains related in a death explanation was a posterior granulomatous lung inflammation after finding affected tissular lung areas or pneumonitis due to foreign bodies reaction from a water aspiration of microalgae and pollen grains (near-drowning event) [15]. In our present study, however, due to the long PMI, no histopathologic information could be considered to address a conclusion of asphystic death.

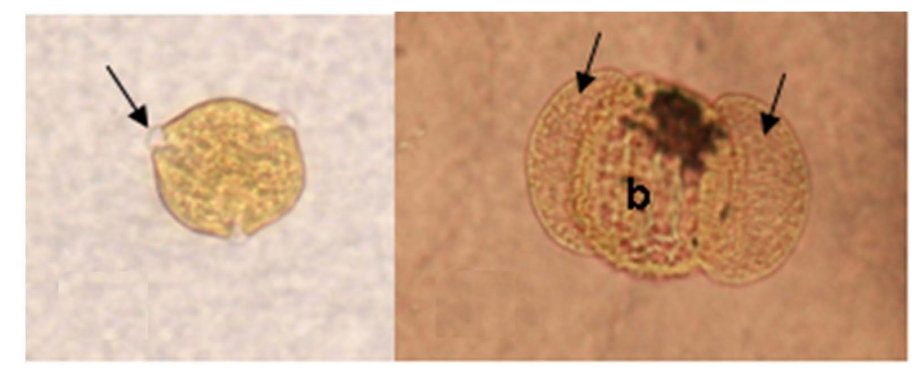

(A)

(B)

Figure 1. Light micrographs (40× magnification) of the plant groups (type, $\mathrm{t}$ ). (A) Trifolium t. pollen grain trizonocolporate with three apertures (arrow) in subtriangular polar view; and (B) Pinus t. grain with the pollen body (b) and two air sacs (arrows).

Table 1. Identified pollen types (t), family and species approximation, in water medium and organs (spleen, lung) are shown. $\mathrm{N}$ represents the number of specimens found.

\begin{tabular}{cccc}
\hline Samples & Water medium (N) & Spleen (N) & Lung (N) \\
\hline Types & Cytisus t. (2) & Cytisus t.(5) & Cytisus t. (3) \\
& Trifolium t. (3) & Trifolium t.(3) & Trifolium t. (5) \\
& Quercus t. (2) & Pinus t. (1) & Pinus t. (1) \\
& & Rosaceae (1) \\
& & Quercus caducifolium (2) \\
\hline
\end{tabular}


Mature pollen exines are composed of a rigid structural substance called sporopollenin and such contains aliphatic double bonds, closely packed anionic sites on high molecular weight molecules, which permit high resistance to environmental conditions [16]. In our case, it is possible that the nitric acid in contact with Tris-ClH buffer could have eliminated some more pollen specimens possibly present in the organs at the samples homogenization, prior microscopy, considering that sporopollenin is the substance remaining when other pollen wall materials are removed by acid lysis (A. Heredia-Bayona 2009, pers. comm.). It is important to account that current pollen preparation for taxonomic purposes follows a less aggressive method of deflocculation with potassium hydroxide, acetylation to remove cellulose and organic matter, and a final silicate removal step with hydrofluoric acid [2]. In the present case, however, no samples homogenization for pollen investigation was done as the study was not expected a priori. There is a potential for powerful investigative evidence of pollen and its application to forensic science [17]. Future investigation on the pollen findings must focus on increasing specimens' number and including acute versus chronic aspiration effects.

\section{Conclusion}

Pollen identification might be useful in near-drowning diagnosis as microscopical examination may reveal aspirated foreign bodies. It is important that forensic palynology should not be used in isolation and so a multidisciplinary approach can be undertaken. Additional molecular methods may be useful but the cost-benefit analysis in current practice is hard to defend. Pollen is one more tool to account in the death investigation.

\section{Acknowledgements}

We thank A. Heredia-Bayona for commentaries and four anonymous referees for final draft suggestions. Authors declare no conflicts of interest.

\section{References}

[1] Mildenhall, D.C., Wiltshire, P.E.J. and Bryant, V.M. (2006) Forensic Palynology: Why Do It and How It Works. Forensic Science International, 163, 163-172. http://dx.doi.org/10.1016/j.forsciint.2006.07.012

[2] Miller Coyle, H., Ladd, C., Palmbach, T. and Lee, H.C. (2001) The Green Revolution: Botanical Contributions to Forensics and Drug Enforcement. Croatian Medical Journal of Forensic Science, 42, 340-345.

[3] Morgan, R.M., Davies, G., Balestri, F. and Bull, P.A. (2013) The Recovery of Pollen Evidence from Documents and Its Forensic Implications. Science and Justice, 53, 375-384. http://dx.doi.org/10.1016/j.scijus.2013.03.004

[4] Lunetta, P., Smith, G.S., Penttila, A. and Sajantila, A. (2003) Undetermined Drowning. Medicine, Science and the Law, 43, 207-214. http://dx.doi.org/10.1258/rsmmsl.43.3.207

[5] Azparren, J.E., Ortega, A., Bueno, H. and Andreu, M. (2000) Blood Strontium Concentration Related to the Length of the Agonal Period in Seawater Drowning in Immersion Cases. Forensic Science International, 108, 51-60. http://dx.doi.org/10.1016/S0379-0738(99)00200-5

[6] Azparren, J.E., Perucha, E., Martínez, P., Muñoz, R. and Vallejo, G. (2007) Factors Affecting Strontium Absorption in Drownings. Forensic Science International, 168, 138-142. http://dx.doi.org/10.1016/j.forsciint.2006.07.003

[7] Hürlimann, J., Feer, P., Elber, F., Niederberger, K., Dirnhofer, R. and Wyler, D. (2000) Diatom Detection in the Diagnosis of Death by Drowning. International Journal of Legal Medicine, 114, 6-14. http://dx.doi.org/10.1007/s004149900122

[8] Piette, M.H.A. and De Letter, E. (2006) Drowning: Still a Difficult Autopsy Diagnosis. Forensic Science International, 163, 1-9. http://dx.doi.org/10.1016/j.forsciint.2004.10.027

[9] Pérez-Cárceles, M.D., del Pozo, S., Sibón, A., Noguera, J.A., Osuna, E., Vizcaya, M.A. and Luna, A. (2012) Serum Biochemical Markers in Drowning: Diagnostic Efficacy of Strontium and Other Trace Elements. Forensic Science International, 214, 159-166.

[10] De la Grand Maison, G.L., Leterreux, M., Lasseuguette, K., Alvarez, J.C., De Mazancourt, Ph. and Durigon, M. (2006) Study of the Diagnostic Value of Iron in Fresh Water Drowning. Forensic Science International, 157, 117-120. http://dx.doi.org/10.1016/j.forsciint.2005.03.016

[11] Denys, L. and Vergruggen, C. (1989) A Case of Drowning-The End of Subatlantic Peat Growth and Related Palaeoenvironmental Changes in the Lower Scheld Basin Based on Diatom and Pollen Analysis. Review of Paleobotany Palinology, 59, 7-36. http://dx.doi.org/10.1016/0034-6667(89)90003-1

[12] Valdés, B., Díez, M.J. and Fernández, I. (1987) Atlas polínico de Andalucía occidental. Instituto de Desarrollo Re- 
gional No. 943. Universidad de Sevilla y Excma, Diputación de Cádiz, Sevilla.

[13] Moore, P.D., Webb, J.A. and Collinson, M.E. (1991) Pollen Analysis. 2nd Edition, Blackwell Scientific, Oxford.

[14] Law, Y.Y. and Jayaprakash, P.T. (2007) Prevalence of Diatom Frustules in Non-Vegetarian Foodstuffs and Its Implications in Interpreting Identification of Diatom Frustules in Drowning Cases. Forensic Science International, 170, 1-7. http://dx.doi.org/10.1016/j.forsciint.2006.08.020

[15] Mangge, H., Plecko, B., Grubbauer, H.M., Popper, H., Solle-Jüttner, F. and Zach, M. (1993) Late-Onset Military Pneumonitis after Near Drowning. Pediatric Pulmonology, 15, 122-124. http://dx.doi.org/10.1002/ppul.1950150210

[16] Southworth, D. (1974) Solubility of Pollen Exines. American Journal of Botany, 61, 36-44. http://dx.doi.org/10.2307/2441242

[17] Walsh, K.A.J. and Horrocks, M. (2008) Palynology: Its Position in the Field of Forensic Science. Journal of Forensic Science, 53, 1053-1060. 